\title{
Publication Patterns in 3 Prominent Educational Psychology Journals: The Geography of Editors, Advisors, Authors, and Participants
}

\author{
Steven R. Yussen \\ Institute of Child Development, The University of Minnesota, Minneapolis, USA \\ Email: syussen@umn.edu
}

Received October 2014

\begin{abstract}
This article considers the publication practices of 3 leading journals in Educational Psychology, for the 6-year period 2008-2013, to determine their representation of countries throughout the world among the editors, editorial board members, authors, and the participants in the samples (the samples of participants based on a random subset of the articles published). The journals considered are: 1) Journal of Educational Psychology (JEP); 2) Contemporary Educational Psychology (CEP); and 3) The British Journal of Educational Psychology (BJEP). The journals published in the United States (JEP and CEP) have a 50 - 60 percent focus on individuals and participants in the United States. For BJEP, the United Kingdom accounts for about a third of authors and participants. Significantly more non-English speaking European countries are represented in the BJEP than in the two American journals. In all three countries, Asia, Africa, and Central and South America are significantly under-represented in the authors and participants of studies.
\end{abstract}

\section{Keywords}

Educational, Psychology, Research, International

\section{Introduction}

Some years ago, Arnett [1] complained that the publication practices of major journals published by the American Psychological Association create a pattern of ignoring most of the world outside the English speaking United States. Analyzing the 6-year period of 2003-2007, for 6 major journals in different fields of psychology, he found that almost all of the journal editors and editorial board members (or advisory boards) were affiliated with US universities. The same was true of the affiliations of the authors of research articles published in the journals and the participants in the research studies reported in the articles. Some of the individuals and participants (from 10 - 20 percent of the cases) were other English speaking countries (e.g., Canada, England, Australia) and European countries (e.g., Germany, Netherlands, Norway). Rarely were there individuals or participants repre- 
sentating the populous Asian, African, or Central or South American regions of the world. His paper sparked considerable interest and debate (e.g., [2] [3]), about whether psychological science is seriously flawed, or whether these findings understate the true international nature of the field. One journal considered in the Arnett [1] study is the Journal of Educational Psychology (JEP). All of the editors and editorial board members of that journal were from the United States and almost three quarters of the first authors of articles were affiliated with US universities; almost all of the remaining authors were affiliated with universities in other English speaking countries (14 percent) or European universities (11 percent). The samples in the reported research studies followed a nearly identical pattern (e.g., almost three quarters drawn from the US population). Here, we report a study undertaken to address the following questions as they pertain specifically to the field of Educational Psychology. 1) Nearly a decade later, would we find evidence of increased international representation of editors, authors, and research participants in the Journal of Educational Psychology (JEP). This change might be expected, given the increased pattern of globalization and communication in the world (e.g., [4]) and the increased interest in the educational practices and successes of countries worldwide (e.g., [5]). 2) Second, would we find the pattern of results for JEP discerned by Arnett [1] to be unique to that journal, or is there a similar geographical narrowness in the publication practices of other leading English language journals? 3) Finally, considering other English language journals in the field, is this observed narrowness greater among journals published in the United States as compared with those published elsewhere.

\section{Method}

\subsection{The Journals Selected}

To answer these questions, we selected 3 prominent English language journals, two from the United States-The Journal of Educational Psychology (JEP) and Contemporary Educational Psychology (CEP); both cover a wide range of topics in the field (as opposed to specializing, for example in reading or mathematics learning) and both were in the top 10 of 50 educational psychology journals in the 2013 Web of Science citation analysis. A third journal, the British Journal of Educational Psychology (BJEP), has a long and venerable history, is similarly broad in its research coverage, and might, in contrast to the US journals selected, have a more international pull due to its proximity to Europe and its history as a colonial power elsewhere in the world.

\subsection{The Analysis of the Journals}

The six year period of 2008-2013 was selected for the analysis of the journals, reflecting the most recent 6-year period for which complete year-long publication cycles are available. For each of the 3 principal journals, we recorded the countries for which editors, associate editors, editorial board members (or consulting editors, if this category was used), and authors can be identified, based on their institutional affiliations-the same procedure followed by Arnett [1]. We found that the affiliation of the authors is a near perfect predictor of where participants are selected for the research (e.g., a United States affiliated author studies individuals in the United States; someone affiliated with a university in Germany studies individuals in Germany).

\section{Results}

\subsection{Editors and Editorial Board Members}

We first report the affiliations of editors and editorial board members for each journal, for the year 2013. See Table 1. For JEP, there are 12 editors; 10 (83\%) are from the United States, $1(8 \%)$ is from Germany and 1 is from England (8\%). The journal lists 112 consulting editors (editorial board members), of which 87 (78\%) are from the United States, another 9 (8\%) are from other English speaking countries, 7 (6\%) are from non-English speaking European countries, 4 (3\%) are from Asian countries, and 1 is from the Middle East. For CEP, there are 3 editors; 2 (66\%) are from the US and 1 (33\%) is from Canada. There are 80 individuals listed on the editorial board; 62 of these are from the United States (78 percent), 5 are from other English speaking countries (6\%), 11 are from non-English speaking European countries (14\%), and 2 are from Asia (2\%). For the BJEP there are 17 editors; 9 (53\%) are from the United Kingdom, 6 (35\%) are from other English speaking countries, and $2(12 \%)$ are from non-English speaking European countries. There are 9 editorial board members (advisory board); 5 (56\%) are from the United Kingdom, 1 (11\%) is from Canada, 2 (22\%) are from non-English speaking European countries, and one is from Asia (11\%). 
Table 1. Geographic affiliation of editors, editorial advisors, and first authors of articles.

\begin{tabular}{|c|c|c|c|c|}
\hline \multirow{2}{*}{$\begin{array}{c}\text { Measure and Journal } \\
\text { EDITORS }\end{array}$} & \multicolumn{4}{|c|}{ Geographic Affiliation } \\
\hline & US OR UK (a) & OTHER ENGL SPEAKING & EUROPE NON ENGL & ASIA \\
\hline$J E P(\mathrm{c})$ & $83 \%(10)(b)$ & $8 \%(1)$ & $8 \%(1)$ & \\
\hline CEP & $66 \%(2)$ & $33 \%(1)$ & & \\
\hline$B J E P$ & $53 \%(9)$ & $35 \%(6)$ & $12 \%(2)$ & \\
\hline \multicolumn{5}{|l|}{ EDITORIAL BOARD } \\
\hline$J E P$ & $81 \%(87)$ & $8 \%(9)$ & $7 \%(7)$ & $3 \%(4)$ \\
\hline CEP & $78 \%(62)$ & $6 \%(5)$ & $14 \%(11)$ & $2 \%(2)$ \\
\hline$B J E P$ & $56 \%(5)$ & $11 \%(1)$ & $22 \%(2)$ & $11 \%(1)$ \\
\hline \multicolumn{5}{|l|}{ FIRST AUTHORS } \\
\hline JEP & $60 \%(244)$ & $13 \%(54)$ & $20 \%(83)$ & $5 \%(21)$ \\
\hline CEP & $50 \%(89)$ & $16 \%(28)$ & $25 \%(45)$ & $7 \%(12)$ \\
\hline BJEP & $33 \%(73)$ & $18 \%(40)$ & $40 \%(88)$ & $7 \%(16)$ \\
\hline
\end{tabular}

The numbers are for the USA for the journals JEP and CEP and for the United Kingdom for BJEP; The numbers show percentages (and number of cases in parentheses); JEP = Journal of Educational Psychology; CEP = Contemporary Educational Psychology; BJEP = British Journal of Educational Psychology.

\subsection{Authors}

Next, we report the affiliations of the first authors of the sample of research papers examined in the journals (we excluded editorials, meta-analyses, introductions to special sections or issues, and other non data based research reports; these accounted for less than $10 \%$ of the published articles in each journal). These data are also summarized in Table 1. JEP generally published between 15 and 21 empirical research articles in each of the 4 issues for each of the 6 years examined, for a total of 402 articles. The geographic location of first authors is a follows: The United States accounts for 60 percent of the first authors of all articles reported in the journal over the 6 year period, while other English speaking countries account for 13\% of the first authors, Europe (non English speaking countries) accounts for $20 \%$ of first authors, and Asia for $5 \%$ of the first authors. CEP generally published between 5 and 10 empirical research articles in each of the 4 issues for each of the 6 years examined for a total of 174 articles. The geographic location of first authors is as follows: The United States accounts for 50\% of the first authors, while other English speaking countries account for $16 \%$ of first authors, European (non English speaking countries) account for $25 \%$ of first authors, and Asia accounts for $7 \%$ of the first authors. The $B J E P$ generally published between 8 and 10 empirical research articles in each of the 4 issues for each of the 6 years examined for a total of 217 articles. The geographic location of first authors is as follows: There were 33\% from Great Britain, 18\% from non British, English speaking countries, 40\% from non English speaking European countries, and 7\% from Asian countries.

\subsection{Participants}

We are in the process of analyzing the full set of studies to characterize the geographic location of the participants sampled in each research study reported in each of the journals, for the full 6-year period. The breakdowns closely resemble the percentages reported in the preceding section for the geographic location of first authors of articles, for each journal, and for each region of the world. In no case (given journal, given year), have we yet identified a deviation of more than 10 percent. Variations were generally the result of multiple authors of the same article having different geographic locations (e.g., Canada and France), or authors having multiple affiliations (e.g. both a British and an Australian university appointment). Some of the articles included participant samples that came from multiple countries. 


\section{Discussion}

One finding consistent with the earlier analysis of APA journals by Barnett, is that the Journal of Educational Psychology is still primarily in the editorial hands of academics associated with organizations in the United States. However, unlike the publication practices in the earlier 2000s, there are a significant number of international editorial board members making up more than a fifth of this group, most of them from other English speaking countries or Europe. Contemporary Educational Psychology, the other highly cited US based journal in the field, in many respects looks like a clone of JEP. With an admittedly smaller group of editors (just 3 , whereas JEP has 12), it is all North American in its leadership (2 from the US, 1 from Canada). And like JEP, this journal relies on a significant number of editorial advisors from other English speaking countries and Europe (almost a fifth). Neither journal has many editorial advisors from Asian countries; none are from the near East or Africa and none are from Central or South America.

The British Journal of Educational Psychology clearly has a different international tone than the two US based journals. Among the editors, fewer than half come from Britain itself, and among the editorial board members, just over half come from Great Britain. Large percentages of scholars from other English speaking countries and Europe take up almost all of the remaining editorial or editorial board member slots. As with the 2 American journals, there is no representation from several parts of the world (the Near East, Africa, Central or South America) among the editors, and little representation from Asia.

Turning to authorship of research articles published in the 3 journals, the patterns look similar to the patterns seen in the geographic distribution of editors and editorial board members, with two notable exceptions. In JEP, a higher percentage of studies are led by first authors from outside the United States (more than 30 percent for each journal), as compared with the findings for editors and editorial board members, including a higher percentage from Asia. Again, the near and Middle East and Africa and Central and South America are essentially unrepresented entirely for both JEP and CEP. Similarly, in the British journal, BJEP, in contrast to the editorial and editorial board make-up, a high percentage of studies are from non British authors (about 66\%), many from other English speaking countries and Europe, and a modest portion from authors affiliated with Asian universities. The near and Middle East and Africa and Central and South America, as in the case of the 2 American journals, are not well represented.

Finally, considering the actual participants in the research studies, based on our preliminary analysis, we note a pattern similar to that reported for the geographic affiliation of authors. A close look suggests, however, an even greater international tone to each of the journals than might be evident in the sheer percentages reported. Some of the articles, for example, report on language studies representing different societies, but with data collected in one location (for example studying how Canadians learn Chinese or German), or the learning of language among new immigrants from several parts of the world (but studied in one country). There is also some degree of global blurring among authors and participant samples, for example, in cases where multiple authors of a single study come from multiple countries, but only participants from one of the countries is selected for the research investigation.

To answer the 3 questions posed at the outset of the article, we conclude that: 1) There has been some movement, during the past decade, for American journals, both of those studied here, in the field of Educational Psychology, to expand the international scope of their publication practices. However, much of the world is still basically ignored. 2) The publication practices of JEP are not dramatically different from that of the other high profile, highly cited educational psychology journal examined here, CEP; each covers (or fails to cover) the world with its editors, editorial board members, authors, and research participants, in highly similar ways. 3) For at least the one other prominent English language journal studied here, the $B J E P$, it appears more international in tone than do the American journals. The BJEP gives over a minority of its journal space and pages to academics from the UK, with wider attention to Europe. It, too, however, suffers from essentially ignoring the same regions of the world as do the 2 American journals.

\section{References}

[1] Arnett, J.J. (2008) The Neglected 95\%: Why American Psychology Needs to Become Less American. American Psychologist, 64, 571-574. http://dx.doi.org/10.1037/0003-066X.63.7.602

[2] Haeffel, G.J., Thiessin, E.D., Campbell, M.W., Kaschak, M.P. and McNeil, N.M. (2009) Theory, Not Cultural Context, Will Advance American Psychology. American Psychologist, 64, 570-571. http://dx.doi.org/10.1037/a0016191 
[3] Webster, G.D., Nichols, A.L. and Schember, T.O. (2009) American Psychology Is Becoming More International. American Psychologist, 64. http://dx.doi.org/10.1037/a0016193

[4] Friedman, T. (2005) The World Is Flat: A Brief History of the Twenty-First Century. Farrar, Strauss and Giroux, New York.

[5] Mullis, I.V.S., Martin, M.O., Foy, P. and Drucker, K.T. (2012) PIRLS 2011 Results in Reading. TIMMS and PIRLS International Study Center, Boston College, Chestnut Hill. 